\title{
Toxoplasma gondii bradyzoites and tachyzoites isolation from vitreous of atypical necrotizing retinitis
}

\author{
Ranju Kharel(Sitaula) $)^{1 *}$, Sagun Narayan Joshi ${ }^{1}$, Ranjit Sah ${ }^{1,3}$, Sushila Khadka ${ }^{1,3}$, Anadi Khatri(KC) ${ }^{2}$ \\ and Bharat Mani Pokharel ${ }^{3}$
}

\begin{abstract}
Background: Detection of Toxoplasma gondii cysts in vitreous of immunocompetent patient with necrotizing retinitis is extremely rare. We herein report the isolation of Toxoplasma bradyzoites and tachyzoites from the vitreous of healthy person.

Results: A 19-year-old immunocompetent female presented with sudden loss of vision in left eye since 1 week. The BCVA was $6 / 6$ and HM in right and left eye. The left eye finding was suggestive of diffuse necrotizing retinitis with retinal detachment. The IgM and IgG for TORCH infection were negative and HIV, HCV and HBsAg tests were also non reactive. The patient underwent diagnostic and therapeutic vitrectomy with silicon oil installation. The vitreous toxoplasma lgG titre was found to be significantly raised to 1:16. Bradyzoites of toxoplasma were identified in H\&E staining and tachyzoites of Toxoplasma were identified in Giemsa staining of vitreous sample. She received oral clindamycin and oral corticosteroid but the vision could not be restored in left eye.

Conclusion: Hence, atypical toxoplasmosis with necrotizing retinitis is a fulminant condition with the diagnostic
\end{abstract} and therapeutic challenge.

\section{Introduction}

Toxoplasma gondii (T. gondii) infects up to a third of the world's population [1]. This prevalence can be much higher in the areas where hygiene is poor, or raw meat is routinely ingested. Around $1-3 \%$ of the infected individuals may develop potentially blinding inflammatory eye disease [2].

Toxoplasmosis is one of the most common global zoonoses and can infect any part of the body. They have a special affinity to the eye-specifically to the tissues of the nervous system including the retina. Since Toxoplasma is an intracellular parasite, the retina can sustain the primary insult and can manifest as necrotizing retinitis [2].

The diagnosis is usually based on the clinical appearance of the fundus lesion. Serological tests, imaging techniques, polymerase chain reaction (PCR), histological

* Correspondence: helloranju50@gmail.com

${ }^{1}$ B.P. Koirala Lions Centre for Ophthalmic Studies, Maharajgunj Medical Campus, Department of Ophthalmology, Institute of Medicine, Tribhuvan University, Maharajgunj, Kathmandu, Nepal

Full list of author information is available at the end of the article demonstration of the parasite, or isolation of the organism usually aid in reaching the definitive diagnosis.

However, it must be noted that the clinical diagnosis of ocular toxoplasmosis is supported by laboratory tests only in $60-85 \%$ of cases. This is mainly because the sensitivity and specificity of these tests depend on the time of sampling [3].

Demonstration of $T$. gondii cysts within the necrotic retina via biopsy is confirmatory but is rare and extremely difficult to perform $[4,5]$. The tachyzoites are known to be capable of independent migration across human vascular endothelium [6]. This could be one of the reasons why very few reports are available on demonstration of Toxoplasma organisms in tissue biopsies/cytology $[7,8]$, necropsy material [9], or enucleated eyes $[10,11]$. We hereby, report the confirmation of ocular toxoplasmosis by the isolation of Toxoplasma tachyzoites and bradyzoites from the vitreous of an immunocompetent person suspected with unilateral necrotizing retinitis. Written consent from the patient and ethical approval from the Institutional Review Board were obtained. 


\section{Findings}

A 19-year-old immunocompetent female presented with painful diminution of vision in the left eye since 10 days. It had a sudden onset with rapid progression. It was not associated with floaters or visual phenomena during the initiation or course of the symptoms. She denies any history of trauma, allergy, or systemic associations except for the history of jaundice 1 month back from which she has now made a total recovery. She is a waitress by profession, non-vegetarian, and gives the history of frequent consumption of undercooked meat of goat, pork, and buffalo.

On examination, vision in the right eye (RE) was $6 / 6$ and in the left eye (LE) was perception of light (PL) with accurate projections. The right eye had grossly normal anterior and posterior segment findings. On the examination of the left eye, there was the presence of circumcorneal congestion; mutton-fat keratic precipitates over the endothelium and Koeppe's nodules at the pupillary margin of the iris (Fig. 1). The reaction in the anterior chamber was intense with cells $4+$ and flare $4+$.

On the examination of the posterior segment, the eye had $4+$ vitreous haze and poor red reflex. Further details of the fundus could not be appreciated (Fig. 2).

Intraocular pressure was $15 \mathrm{mmHg}$ in the $\mathrm{RE}$ and $13 \mathrm{mmHg}$ in the LE. The ultrasonography of the left eye was mandated immediately. It revealed a band-like hyperechogenic structure extending from the vitreous base towards the posterior hyaloid surface converging around optic nerve head. This radiological finding was persisting in low gain (Fig. 3) which suggested of vitritis along with wide anterior and narrow posterior retinal detachment of funnel shape.

A provisional diagnosis of acute granulomatous panuveitis with a retinal detachment of the left eye was made with acute retinal necrosis (ARN) as a probable cause.

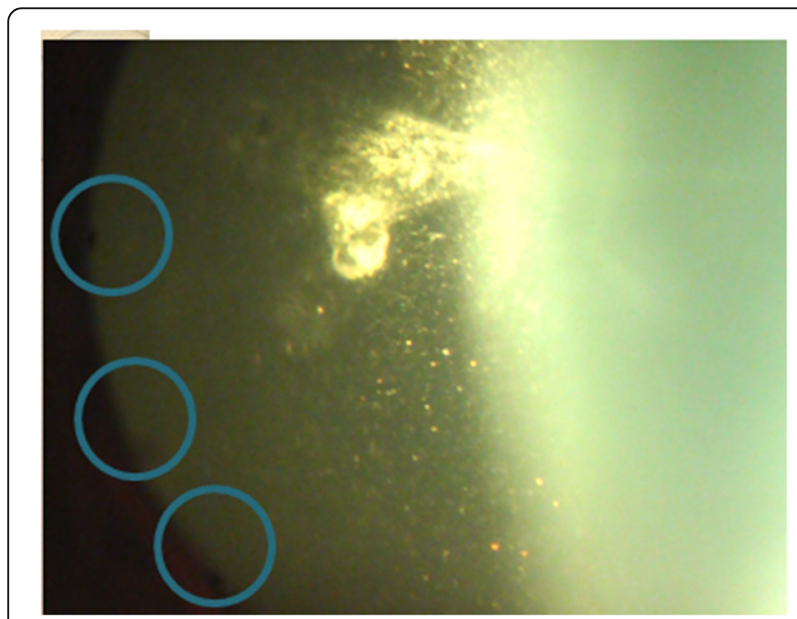

Fig. 1 Mutton-fat KPs (brown outline) and Koeppes' nodules (blue outline)

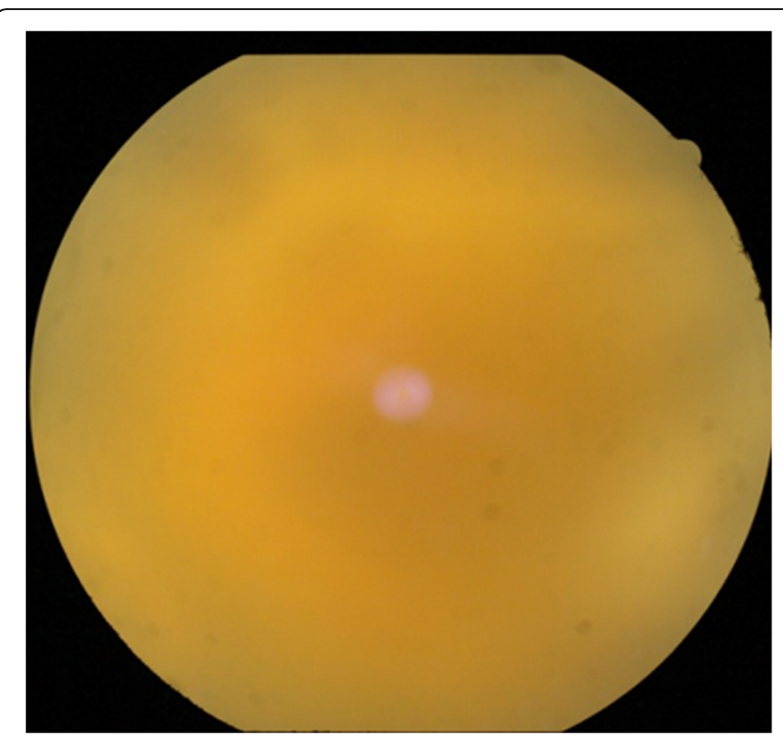

Fig. 2 Poor fundal glow in the left eye

Tailored laboratory investigations were sent, and treatment with oral acyclovir and oral corticosteroid was started immediately. The laboratory reports for IgM and IgG for TORCH infection were negative. Serological tests for HIV, HCV, and HBsAg were also negative. PCR for herpes virus family could not be performed due to unavailability. The patient then underwent diagnostic and therapeutic vitrectomy using $23 \mathrm{G}(25 \mathrm{~mm})(0.6 \mathrm{~mm}$ bore) cutter via the pars plana route. There was the presence of dense vitreous exudate with multiple atrophic holes near the ora with near total retinal detachment. The optic nerve was found to be slightly pale. The vitreous sample $(0.5 \mathrm{ml})$ was retrieved and sent for cytology and toxoplasma IgG titer.

Toxoplasma IgG vitreous titer was raised significantly to 1:16. To everyone's surprise, the microbiological examination of the vitreous yielded bradyzoites of

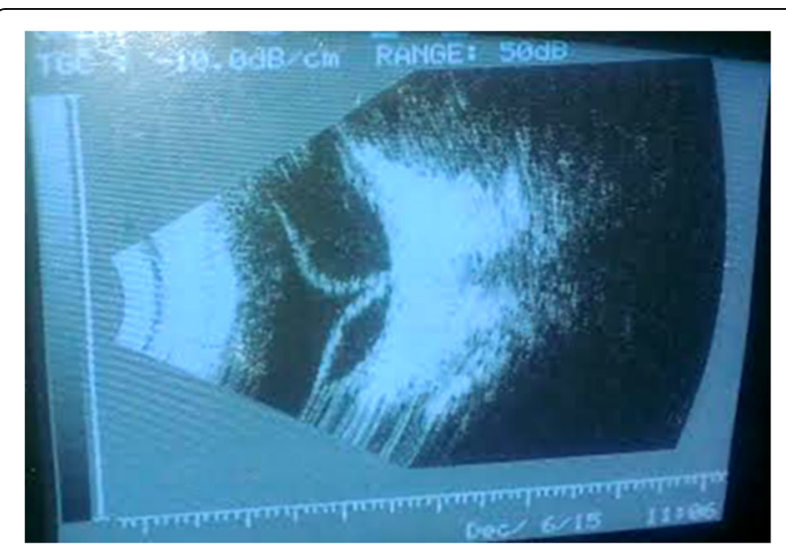

Fig. 3 Band-like hyperechogenic structure extending from the vitreous base towards the posterior hyaloid surface and optic nerve head 


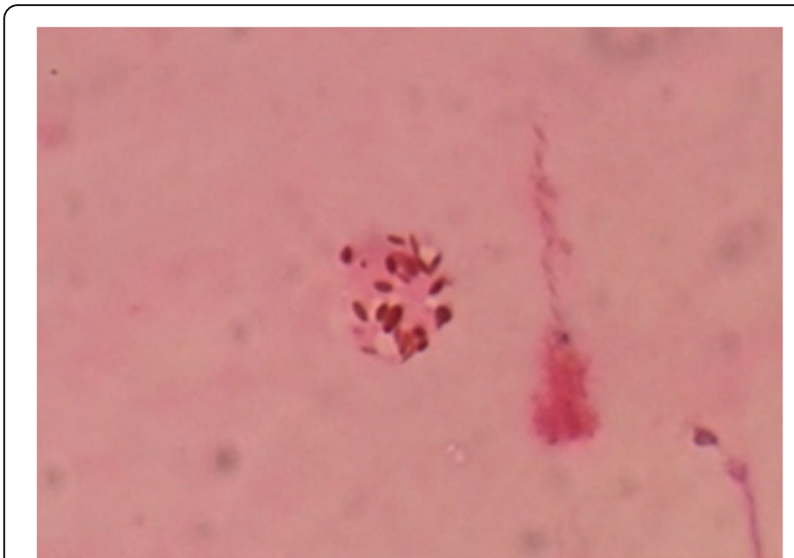

Fig. 4 Bradyzoites of Toxoplasma were seen in H\&E staining

Toxoplasma in H\&E staining (Fig. 4) and tachyzoites in Giemsa staining (Fig. 5). This confirmed the diagnosis of atypical ocular toxoplasmosis.

The treatment plan was revised and the patient was started with oral clindamycin and oral corticosteroid, but the visual loss was not permanent as the anatomical integrity of the retina had succumbed to the damage. A pars plana approach to save the retina from further damage was attempted, and silicon oil instillation was triedbut in vain (Fig. 6).

\section{Discussion}

Necrotizing retinopathies represent a diagnostic and therapeutic challenge for all ophthalmologists. Commonest suspected cause is acute retinal necrosis (ARN) which carries a poor visual outcome and a high rate of complications, such as rhegmatogenous retinal detachment [12]. However, as noted in our case, other infectious and non-infectious causes like toxoplasma retinitis and other great mimickers such as syphilis, Behcet's disease, intraocular lymphoma, and aspergillosis also have to be borne in mind. Inadvertent use of antiviral agents

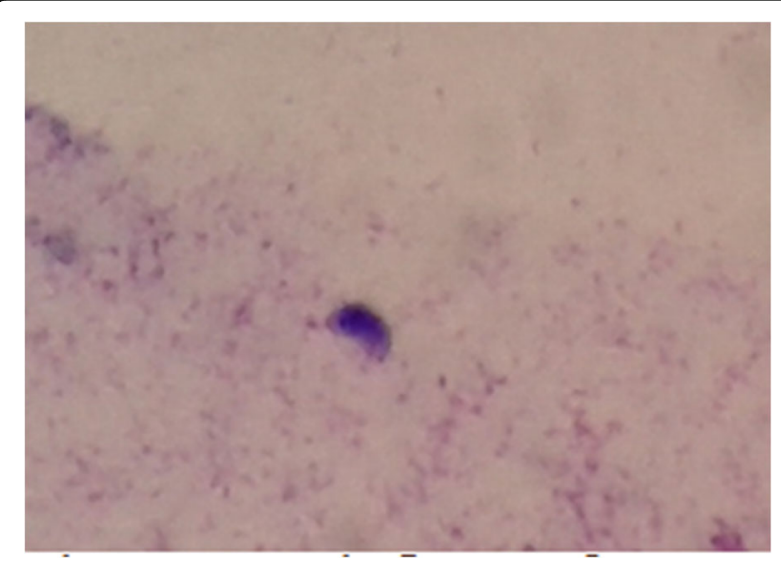

Fig. 5 Tachyzoites of Toxoplasma were seen in Giemsa staining

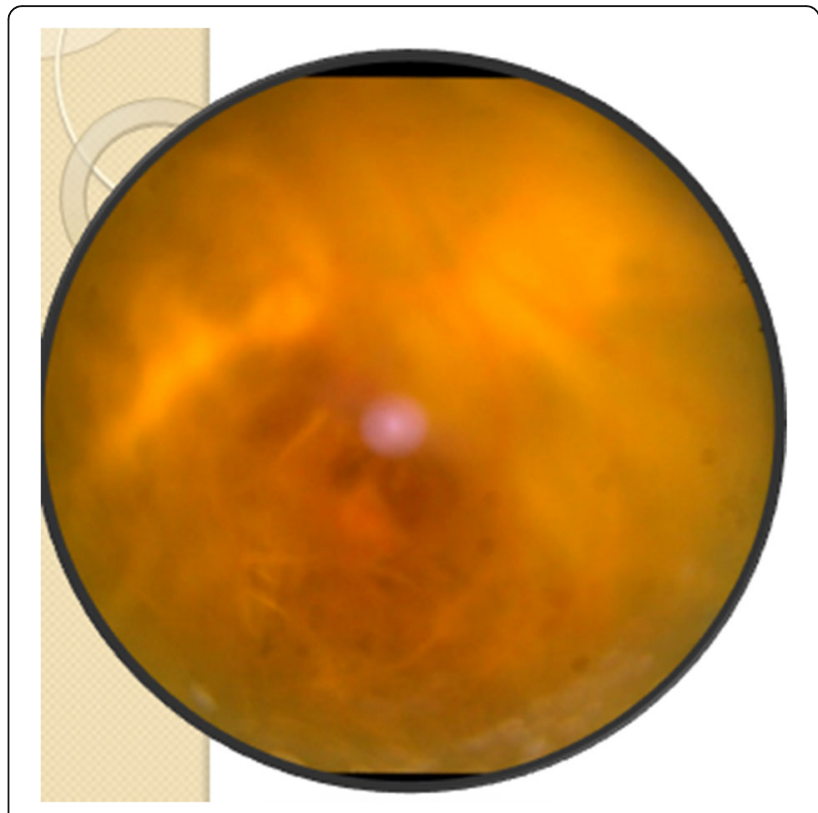

Fig. 6 Poor fundal visualization even after vitrectomy

and corticosteroids can be prevented by exploring the causes of necrotizing retinitis besides ARN.

Parasite of $T$. gondii is rarely identified in aqueous/vitreous humor samples from patients with active ocular toxoplasmosis mainly because the parasite proliferation occurs only during the early phase of infection, but the retinal damages are probably caused by subsequent inflammatory responses [13].

Due to the atypical clinical presentations, positive history of intake of undercooked meat, poor response to therapy, and a high clinical suspicion of atypical ocular toxoplasmosis in an immunocompetent person resorted us to proceed to vitreous cytological analysis. The seroprevalence in some part of the world including Nepal can be as high as $50 \%$ due to ingestion of water or vegetables contaminated with $T$. gondii oocysts and ingestion of undercooked/raw meat-which are a common dish in some Nepalese community [14].

Though the presence of any titer of IgG against Toxoplasma gondii in aqueous or vitreous sample is highly indicative of ocular toxoplasmosis, the sensitivity and the specificity of intraocular antibody detection have been reported only to be 63 and $89 \%$, respectively [13], but positivity can range up to $95 \%[15,16]$. However, the drawbacks are due to the limitations of the volume of ocular fluid that can be withdrawn, presence low antibody levels present within the specimen, and risk of complications like cataract and endophthalmitis [13]. While PCR is an easier technique for the detection of Toxoplasma DNA, the Goldmann-Witmer coefficient (GWC) detects intraocular antibody production and has shown superior 
results in diagnosing ocular toxoplasmosis when compared to PCR of aqueous humor [17].

Few reports in the literature have described the isolation of $T$. gondii from the eye following an episode of active retinal disease $[18,19]$. Usually, it is the proliferative tachyzoite stage where the viable parasites could be isolated. We could isolate both the tachyzoite and bradyzoites form of $T$. gondii in the active stage. This could be due to the rapid transitional stage of tachyzoite to bradyzoites, with the formation of tissue cysts [20].

The help and meticulousness of cytopathologist and microbiologist are equally important to achieve a quick and accurate diagnosis as in our situation. With the advancement in sampling techniques, it may one day be possible to demonstrate this illuding protozoan in a greater proportion of ocular samples sent to the cytology laboratory.

\section{Conclusion}

Demonstration of cyst of $T$. gondii in an ocular fluid sample is extremely difficult with strong suspicion and meticulous search-a timely confirmation of the disease may prevent permanent vision loss.

\section{Authors' contributions}

RKS, SNS, and AK were involved in the case evaluation and medical and surgical management. RS, SK, and BMP carried out the laboratory diagnosis and isolated the organism. RKS and AK drafted the manuscript. All authors read and approved the final manuscript.

\section{Ethics approval and consent to participate}

Ethical approval from the Institutional review Board and informed written consent was obtained from the patient.

\section{Competing interests}

The authors declare that they have no competing interests.

\section{Publisher's Note}

Springer Nature remains neutral with regard to jurisdictional claims in published maps and institutional affiliations.

\section{Author details}

'B.P. Koirala Lions Centre for Ophthalmic Studies, Maharajgunj Medical Campus, Department of Ophthalmology, Institute of Medicine, Tribhuvan University, Maharajgunj, Kathmandu, Nepal. ${ }^{2}$ Vitreo-Retinal Pathology and Surgery, Lumbini Eye Institute, Lumbini, Nepal. ${ }^{3}$ Department of Microbiology, Institute of Medicine, Tribhuvan University, Kathmandu, Nepal.

Received: 3 October 2017 Accepted: 11 May 2018

Published online: 15 June 2018

\section{References}

1. Nussenblatt RB (2010) Ocular toxoplasmosis. In: Uveitis: fundamentals and clinical practice, 4th edn. 14 pp 190-209

2. Commodaro AG, Belfort RN, Rizzo LV, Muccioli C, Silveira C, Burnier MN Jr et al (2009) Ocular toxoplasmosis: an update and review of the literature. Mem Inst Oswaldo Cruz 104(2):345-350

3. Garweg JG, de Groot-Mijnes JD, Montoya JG (2011) Diagnostic approach to ocular toxoplasmosis. Ocul Immunol Inflamm 19(4):255-261

4. Nijhawan R, Bansal R, Gupta N, Beke N, Kulkarni P, Gupta A (2013) Intraocular cysts of Toxoplasma gondii in patients with necrotizing retinitis following periocular/intraocular triamcinolone injection. Ocul Immunol Inflamm 21(5):396-399
5. Brezin AP, Kasner L, Thulliez P, Li Q, Daffos F, Nussenblatt RB et al (1994) Ocular toxoplasmosis in the fetus: immunohistochemistry analysis and DNA amplification. Retina 14(1):19-26

6. Furtado JM, Bharadwaj AS, Chipps TJ, Pan Y, Ashander LM, Smith JR (2012) Toxoplasma gondii tachyzoites cross retinal endothelium assisted by intercellular adhesion molecule-1 in vitro. Immunol Cell Biol 90(9):912-915

7. Greven CM, Teot LA (1994) Cytologic identification of Toxoplasma gondii from vitreous fluid. Arch Ophthalmol 112(8):1086-1088

8. Adán A, Sole M, Mateo C, Jean AS, Alforja S (2012) Cytologic identification of Toxoplasma gondii from subretinal aspirate. Acta Ophthalmol 90(4):392-393

9. Yeo JH, Jakobiec FA, Iwamoto T, Richard G, Kreissig I (1983) Opportunistic toxoplasmic retinochoroiditis following chemotherapy for systemic lymphoma: a light and electron microscopic study. Ophthalmology 90(8):885-898

10. Rao NA, Font RL (1977) Toxoplasmic retinochoroiditis: electron-microscopic and immunofluorescence studies of formalin-fixed tissue. Arch Ophthalmol 95(2):273-277

11. Belfort RN, Rasmussen S, Kherani A, Lodha N, Williams G, Fernandes BF et al (2010) Bilateral progressive necrotizing retinochoroiditis in an immunocompromised patient: histopathological diagnosis. Acta Ophthalmol 88(5):614-615

12. Balansard B, Bodaghi B, Cassoux N, Fardeau C, Romand S, Rozenberg F et al (2005) Necrotising retinopathies simulating acute retinal necrosis syndrome. Br J Ophthalmol 89(1):96-101

13. Villard O, Filisetti D, Roch-Deries F, Garweg J, Flament J, Candolfi E (2003) Comparison of enzyme-linked immunosorbent assay, immunoblotting, and PCR for diagnosis of toxoplasmic chorioretinitis. J Clin Microbiol 41(8):3537-3541

14. Rai SKUM, Shrestha HG (2003) Toxoplasma infection in selected patients in Kathmandu, Nepal. Nepal Med Coll J 5(2):89-91

15. Kijlstra A, Luyendijk L, Baarsma G, Rothova A, Schweitzer C, Timmerman Z et al (1989) Aqueous humor analysis as a diagnostic tool in toxoplasma uveitis. Int Ophthalmol 13(6):383-386

16. Fawzy M, Mahmoud L, El Gindy A, Hegab M, Bahgat M (1998) Value of estimating intraocular antibody production in diagnosis of typical and atypical lesions of ocular toxoplasmosis. J Egypt Soc Parasitol 29(3):735-743

17. De Groot-Mijnes JD, Rothova A, Van Loon AM, Schuller M, Ten Dam-Van Loon NH, De Boer JH et al (2006) Polymerase chain reaction and Goldmann-Witmer coefficient analysis are complimentary for the diagnosis of infectious uveitis. Am J Ophthalmol 141(2):313-318

18. Holland GN (2009) Ocular toxoplasmosis: the influence of patient age. Mem Inst Oswaldo Cruz 104(2):351-357

19. O'Connor G (1974) Manifestations and management of ocular toxoplasmosis. Bull N Y Acad Med 50(2):192

20. Sahm M, Fischer H-G, Gross U, Reiter-Owona I, Seitz HM (1997) Cyst formation by Toxoplasma gondii in vivo and in brain-cell culture: a comparative morphology and immunocytochemistry study. Parasitol Res 83(7):659-665

\section{Submit your manuscript to a SpringerOpen ${ }^{\circ}$ journal and benefit from:}

- Convenient online submission

Rigorous peer review

- Open access: articles freely available online

- High visibility within the field

Retaining the copyright to your article

Submit your next manuscript at $>$ springeropen.com 